\title{
Testing the predictors of boredom at school: Development and validation of the precursors to boredom scalles
}

\author{
Elena C. Daschmann ${ }^{1,2 *}$, Thomas Goetz ${ }^{1,2}$ \\ and Robert H. Stupnisky ${ }^{3}$ \\ 'University of Konstanz, Germany \\ ${ }^{2}$ Thurgau University of Teacher Education, Kreuzlingen, Switzerland \\ ${ }^{3}$ University of North Dakota, Grand Forks, USA
}

\begin{abstract}
Background. Boredom has been found to be an important emotion for students' learning processes and achievement outcomes; however, the precursors of this emotion remain largely unexplored.
\end{abstract}

Aim. In the current study, scales assessing the precursors to boredom in academic achievement settings were developed and tested.

Sample. Participants were 1,380 grade 5-10 students in mathematics classes.

Method. The Precursors to Boredom Scales were tested for structural and convergent validity with multi-level confirmatory factor analyses (ML-CFA), and differences in the perception of the precursors of boredom due to gender were investigated.

Results. The first ML-CFA found support for the structural validity of the Precursors to Boredom Scales. In a second ML-CFA, the newly developed boredom scales showed good convergent validity with several key aspects of instructional quality. Finally, the results supported previous research that found no gender differences in academic selfconcept and interest.

Conclusion. The precursors contained in our scales are empirically separable. Implications of the current findings for research on boredom among students are discussed.

Students often feel bored at school. According to Larson and Richards (1991), students experience boredom $32 \%$ of the time they spend in class. Götz, Frenzel, and Pekrun (2007) found that students are bored during almost half of each lesson on average. Boredom reflects the dissipation of human resources resulting in the ineffective fulfilment

*Correspondence should be addressed to Elena C. Daschmann, Fach 45 University of Konstanz, Universitätsstrasse 10, D-78457 Konstanz, Germany (e-mail: elena.daschmann@uni-konstanz.de). 
of the potentials of young people which modern, achievement oriented societies cannot afford. Specifically, students experiencing high levels of boredom have been found to be at a higher risk of many negative consequences, such as academic problems including low grades, school absenteeism, and drop-out (Robinson, 1975; Wasson, 1981), drug abuse (Johnston \& O'Malley, 1986; Orcutt, 1984; Samuels \& Samuels, 1974), eating disorders (Abramson \& Stinson, 1977; Leon \& Chamberlain, 1973), hostility (Broadbent \& Gath, 1979), depression (Giambra \& Traynor, 1978), and delinquency (Harris, 2000; Vodanovich \& Kass, 1990).

Although boredom is known to be important in achievement settings, there is still much that is unknown about this emotion. According to Pekrun, Goetz, Titz, and Perry (2002), studies examining boredom in learning and achievement settings are relatively rare. One particularly underexplored aspect of boredom is its antecedents or precursors. This lack of research is astonishing because knowledge about how and when boredom occurs would allow researchers and educators to develop and implement boredom reducing intervention programmes in schools. This information could also strengthen the theoretical and practical training of teachers leading to an improved quality of instruction in schools. Therefore, the primary objective of the present study was to increase our knowledge of the precursors of boredom among students.

\section{Theoretical perspectives}

Theories positing the precursors of boredom are rare. Furthermore, the few existing theoretical perspectives of what instigates boredom differ considerably, implying that numerous aspects of classroom instruction may evoke boredom. Fisher (1993) provides a general classification of the causes of boredom. She discriminates among causes of boredom that lie outside the person, such as task and environmental conditions, causes that originate inside the person, such as their personality, and causes that derive from the fit between person and environment. Fisher applies this classification only to professonal or working situations.

This distinction between precursors of boredom may also be adapted to learning and achievement settings. For instance, Pekrun's (2006; see also Pekrun, 2000; Pekrun et al. 2007) control-value theory of achievement emotions integrates the same classification on the development of achievement emotions. This prominent theory therefore provides a valuable theoretical framework which can be applied to explain precursors of boredom in students. Pekrun describes in his theory how students' emotions have individual and social determinants, which both have an influence on causes due to the fit between person and environment. The personality antecedents consist of non-cognitive factors, such as the person's temperament, and situational appraisals, namely control and value appraisals. Environmental influences on students' emotions, such as the quality of their classroom instruction, are also mediated by control and value beliefs. These appraisals, being influenced by both the person and their environment, play a key role in the development of emotions. Therefore, not only students' personalities, but also their cognitions, are important predictors of emotions. Specifically, the extent to which students subjectively value the learning material and perceive control over the situation can facilitate the occurrence of different emotions. According to Pekrun, boredom arises in students if they do not value the learning material and they perceive either too much or too little control over the situation. 
Beyond these global theories on boredom and other academic emotions, there are several more specific theoretical perspectives on antecedents of boredom which contribute additional aspects to our theoretical framework (summarized here chronologically). Robinson (1975) developed a model of boredom at school in which situational and personal precursors at both the proximate and remote levels were outlined. The main proximate causes of boredom were monotonously instructed classes, perceived uselessness of the subject, and a lack of goals. More remote antecedents implied at by the author (although not explicitly stated) stem from the influence of students' home life, parents, peers, and teachers.

Hill and Perkins (1985) also cited monotony as the main cause for the occurrence of boredom. More precisely, 'sensory monotony is neither a necessary nor a sufficient cause of boredom' (p. 221), but rather the subjects' perception of the situation may lead to this emotion if it is interpreted as monotonous. In addition, the authors claim that the occurrence of boredom may be related to the meaningfulness or value of the stimulation. That is, if students perceive a situation as relevant for their needs, it becomes more meaningful to them and therefore it would be less likely to provoke boredom.

Definitions of boredom also often identify causes of this emotion. This should be seen critically because a definition should primarily describe the construct itself and not the factors by which it is caused; nevertheless, one can often deduce which precursors of boredom these authors would predict. Mikulas and Vodanovich (1993), for example, define boredom as 'a state of relatively low arousal and dissatisfaction, which is attributed to an inadequately stimulating situation' (p. 3). This definition implies that students become bored in class when the learning material is not well adjusted to their level of knowledge or achievement.

Overall, previous theoretical perspectives on boredom have identified several precursors to this emotion. Specifically, students should be less bored in classes with low levels of perceived monotony, a factor that can be influenced by teachers' use of an assortment of teaching methods. Another factor that could influence the occurrence of boredom is the degree to which teachers adapt to the demands of their students' achievement potential. Finally, lessons that are perceived as highly useful or valuable and allow students to perceive themselves as moderately in control of the outcome should decrease their experiences of boredom. Therefore, the knowledge of precursors of boredom that are due to the environment or person-environment fit is important to help prevent this emotion in class. On the other hand, boredom due to the students' personality may not easily be reduced by school instruction.

\section{Empirical evidence}

Although several theoretical positions on the precursors to boredom in school are present in the literature, empirical evidence for the assumed mechanisms is greatly lacking. Nonetheless, there are several studies providing partial evidence for some of the precursors mentioned above. Monotony as a cause of boredom was explored in a study by Robinson (1975). He compared students who felt bored frequently versus infrequently on their perception of instruction during class. His results indicated that $66 \%$ of frequently bored pupils, compared with $39 \%$ of infrequently bored pupils, claimed that school was the same everyday. As reasons for their boredom, students had named 'the same thing all the time, teachers going on and on, and lack of variety' (p. 142). 
Experiments by Hill and Perkins (1985) also found support for the hypothesis that subjective monotony is associated with boredom, although boredom was not necessarily produced by physical monotony in stimulation. Furthermore, Fiske and Maddi (1961) found subjective monotony as an antecedent of boredom and that individuals who were bored for this reason to seek alternative and more varied sources of stimulation. Finally, evidence from sensory deprivation studies indicates that an aversive effect of perceived monotony is boredom (Heron, 1957; Solomon, 1972).

Robinson (1975) explored if a lack of meaning or valuing of material could lead to boredom. Indeed, results from his study reflected perceived uselessness of learning material as an important precursor of boredom (see also Fiske \& Maddi, 1961; MortonWilliams \& Finch, 1968). Mitchell (1993) found that meaningful learning material can prevent students from being bored and even enhance their interest. Interestingly, Landon and Suedfeld (1969) found that a lack of meaning was a stronger precursor of boredom than physical monotony. This is in accordance with Titz's (2001) finding of high negative correlations between both interest and intrinsic motivation with boredom in learning situations. Also, Robinson (1975) reported much less boredom among students who reported school to be interesting. The connection between boredom and interest was also reflected in a study by Götz (2004), which showed rather high negative correlations between boredom and the scales for interest in mathematics. ${ }^{1}$

Evidence for the incongruence between difficulty of learning material and student achievement level as a predictor of boredom among students has also been found. For example, Lohrmann (2008) found boredom was likely to occur in situations where students were either over- or under-challenged. Similarly, Titz (2001) detected both low and high competence cognitions to be associated with boredom in learning situations. Finally, Robinson (1975) found that $40 \%$ of students reported " not understanding", "not being any good at", and "not having subjects explained enough"' (p. 142) were causes of boredom. All of these reasons are indicators of students who are bored because of being over-challenged.

Götz (2004) explored the connection between the occurrence of emotions and several characteristics of classroom instruction. He found high negative correlations between boredom and the following aspects of instructional quality: clarity and structuring, elicitation of motivation, and commitment. Also, negative correlations were observed between boredom and disruption during instruction and pace of instruction. These results are in accordance with Lohrmann's (2008) conclusion that students typically cite aspects of instruction when asked for the antecedents of their boredom, as opposed to details relating to the subject matter.

\section{Research objectives and hypotheses}

Based on the limited theoretical background and empirical evidence, the present study examined five research hypotheses that related to our primary objective of empirically

\footnotetext{
'It is important to note that boredom is not simply the 'opposite' of interest (Pekrun, Goetz, Daniels, Stupnisky, \& Perry, 2010); that is, boredom implies more than the absence of interest. Lack of interest can be a cause of boredom, but is not identical to boredom. Lack of interest is affectively neutral and does not cause emotional pain, whereas boredom is emotionally distressing. Due to different affective loads, lack of interest, and boredom also have different motivational consequences. While a lack of interest implies the wish neither to engage with an activity nor to avoid it, boredom typically triggers strong impulses to escape the situation.
} 
investigating the predictors of students' boredom in classrooms by developing scales to assess its theorized precursors. Recent studies have found that academic emotions are largely domain-specific in nature (Goetz, Frenzel, Pekrun, Hall, \& Luedtke, 2007); we therefore focused on the academic domain and more specifically mathematic classrooms, as boredom is believed to occur regularly during the teaching of this subject. It should be noted that the Precursors to Boredom Scales were designed to be easily adapted to academic subjects other than mathematics.

\section{Frequency of boredom}

The first objective was to test the hypothesis that students frequently experience boredom in math class. Götz et al. (2007) and Larson and Richards (1991) both found that students are bored during a substantial amount of class time. We sought to replicate these previous studies and determine what percentage of students experiences this emotion and to what degree.

\section{Structural validity of scales}

A second objective was to test the structural validity of newly created scales that assess the precursors of students' boredom in math class. We hypothesized that the theoretical structure of eight distinct antecedents of boredom would be supported through multilevel confirmatory factor analysis (ML-CFA), which would signify the structural validity of our scales (Byrne, 2001).

\section{Gender differences in scale means}

To further validate the Precursors to Boredom Scales, we tested for gender differences among the boredom antecedents. Although there is a lack of research in this area, empirical evidence on gender differences in students' self-concepts exist that informs our hypotheses. For instance, in mathematics, girls have been found to have lower selfconcepts (Goetz, Frenzel, Hall, \& Pekrun, 2008) and lower interest (Frenzel, Pekrun, \& Goetz, 2007a) than boys, even when controlling for their level of achievement. These differences in math self-concept and interest in mathematics may influence students' methods of interpreting their precursors to boredom. We therefore expected to find gender differences in the mean scores of specific boredom scales. Specifically, we hypothesized that girls would more frequently be bored than boys in math class because they are over-challenged, whereas boys would more frequently be bored than girls due to being under-challenged. Furthermore, we expected boredom in mathematics to be more prevalently among girls than boys because they would perceive a lack of meaning in the course material.

\section{Precursors of boredom and mathematics grades}

To test the ecological validity of the Precursors of Boredom Scales by external criteria, the relationship between students' grades in mathematics and their perceived causes of boredom was investigated. According to the content of the boredom scales, we expected a high negative correlation between mathematics grades and being over-challenged, and a positive correlation between mathematics grades and being under-challenged. 
Precursors of boredom and instructional quality

An additional goal of our study was to investigate the relations between the measured precursors to boredom and several specific aspects of classroom instruction. As Götz (2004) found connections between the occurrence of boredom and characteristics of classroom instruction, we hypothesized that the Precursors to Boredom Scales would show convergent validity with these aspects of instruction. For example, we expected students who perceived a great deal of variety in instruction of their mathematics class to be less frequently bored due to monotony. We would interpret such relations as further indicators of the validity of the Precursors to Boredom Scales.

\section{Method}

\section{Participants and procedure}

Participants for the current study were 1,380 German students $(50.1 \%$ female), with a mean age of 12.56 years $(S D=1.80)$. Students were recruited from 55 classes (grades 5-10, class size: $M=24.64, S D=4.64$ ) representing all three tracks of the German secondary school system. Specifically, 36.1\% of the students attended Hauptschule (lowest or general school, 23 classes), 35.1\% attended Realschule (intermediate or apprenticeship preparatory school, 18 classes), and $28.8 \%$ attended Gymnasium (highest or college preparatory school, 14 classes). A negligible amount of missing data due to student non-response was observed. We found students to fill out the 51 items we used in our analyses with variable diligence: missing responses ranged from $1.9 \%$ for the most commonly missed item to $0.2 \%$ missing for the most commonly answered item.

The Precursors to Boredom Scales involved directly asking students about factors that may elicit boredom. Data collection for the present study was conducted by trained testing personnel using fully standardized student questionnaires. Participants were tested in a classroom setting and took part on a voluntary basis.

\section{Measures}

Academic emotions can be assumed to be domain specific in nature (Goetz et al., 2007). In our questionnaire, we therefore focused on one specific domain, namely the academic domain of mathematics, in which boredom was believed to be experienced regularly (Goetz et al., 2007).

\section{Frequency of boredom}

Two items on a five-point Likert scale ( $1=$ strongly disagree, $5=$ strongly agree $)$ were used to assess the occurrence of boredom during math class. The items were, 'I'm often bored in math class' and 'In math class, I frequently feel bored'. The frequency of boredom items showed a reliability of Cronbach's $\alpha=.91$ (see Hulin et al., 2001, for calculating alpha for two-item scales). The two items were averaged resulting in a range of responses from 1 to 5 .

\section{Precursors to boredom}

To investigate the reasons for boredom in mathematics classes, the eight Precursors to Boredom Scales were developed consisting of self-formulated items. Table 1 shows a sample item, number of items, and descriptive statistics for each scale. When creating 
Table I. Descriptive statistics of the Precursors to Boredom Scales

\begin{tabular}{|c|c|c|c|c|}
\hline Boredom scales & Item examples & $n_{i}$ & $M$ & $S D$ \\
\hline & 'When I'm bored in mathematics class it is because... & & & \\
\hline I. Monotony & ...we always do the same thing in math class.' & 3 & 2.50 & 1.00 \\
\hline 2. Lack of meaning & $\begin{array}{l}\text {...the subject matter of math class has no meaning } \\
\text { in my life.' }\end{array}$ & 4 & 2.23 & 1.00 \\
\hline 3. Opportunity costs & $\begin{array}{l}\text {...I would much rather do something else than sit } \\
\text { in math class.' }\end{array}$ & 2 & 3.57 & 1.21 \\
\hline 4. Being over-challenged & ...the subject matter in math is too difficult for me.' & 4 & 2.30 & 0.95 \\
\hline 5. Being under-challenged & ...the subject matter is too easy.' & 2 & 2.27 & 1.08 \\
\hline 6. Lack of involvement & ...my math teacher never involves us in the lesson.' & 2 & 1.96 & 1.07 \\
\hline 7. Teacher dislike & ...l don't like my math teacher.' & 2 & 2.15 & 1.32 \\
\hline 8. Generalized boredom & ...l'm always bored in school.' & 3 & 1.97 & 0.89 \\
\hline
\end{tabular}

Note. $N=1,380 . M$ and $S D$ refer to the mean score of the items averaged within each scale and can therefore range from $\mathrm{I}$ to 5 .

the boredom scales we referred to our theoretical framework on the precursors of boredom at school (e.g., Fenichel, 1951; Fisher, 1993; Hill \& Perkins, 1985; Mikulas \& Vodanovich, 1993; Pekrun, 2006; Robinson, 1975) and to empirical evidence gained from an interview study by Daschmann, Stupnisky, Nett, Wimmer, and Goetz (2010) in which students and teachers were asked for possible antecedents of boredom. Items were developed to cover the different aspects of each scale. Therefore numbers of items ranged from 2 to 4 , according to the theoretical content of each scale. The items were formulated as attributional statements with a response format consisting of a five-point Likert scale ranging from (1) strongly disagree to (5) strongly agree. The analyses were performed with the mean scores of the items averaged within each scale; therefore the final score for each scale ranged from 1 to 5 .

In the boredom scales, students were asked to what degree their boredom was due to (1) monotony (number of items $n_{i}=3$ ), in order to detect how much perceived monotony in mathematics class leads to boredom among students. The boredom due to (2) a lack of meaning scale $\left(n_{i}=4\right)$ measured the degree to which students' boredom arises if they do not perceive the relevancy of subject matters. The boredom due to (3) opportunity costs scale $\left(n_{i}=2\right)$ measured the extent to which students ascribe their boredom to the fact that they would rather engage in other activities than sit in mathematics class. More specifically, these items conceive how much pupils feel bored because they consider math class as a misuse of their time, in particular if they have more valuable alternative activities to attend to.

The boredom due to ( 4$)$ being over-challenged scale $\left(n_{i}=4\right)$ measured the extent to which students attributed their boredom to the difficulty of mathematics course material and their teacher's explanations being too difficult for them to understand. A boredom due to (5) being under-challenged scale $\left(n_{i}=2\right)$ measured to what degree students felt bored because they do not feel challenged enough. The boredom due to (6) a lack of involvement scale $\left(n_{i}=2\right)$ assessed the extent to which students feel bored when their teacher does not integrate them in class interaction. To determine the degree to which students attribute a feeling of boredom to a lack of sympathy towards their teacher, we developed the boredom due to (7) teacher dislike scale $\left(n_{i}=2\right)$. The last scale, (8) generalized boredom $\left(n_{i}=3\right)$, measured how much students have a habitual feeling of 
boredom and the extent to which they attribute the boredom they experience during mathematics class to this trait.

Mathematics grades

The questionnaire contained two items in which students were asked about their mathematics grades. One item investigated the mathematics grade of the previous year's report paper, the other item asked for the grade in the most recent mathematics test. Response format consisted of a six-point likert scale ranging from (1) insufficient to (6) excellent. The two items were averaged resulting in a range of responses from 1 to 6 $(M=3.87, S D=0.97)$.

\section{Quality of mathematics instruction}

Eight scales assessing instructional quality were included in the questionnaire to validate the Precursors to Boredom Scales. The scales were adapted from those used in the Project for the Longitudinal Analysis of Learning and Achievement in Mathematics (PALMA, cf. Pekrun, vom Hofe, et al., 2007). Table 2 shows example items, number of items, means, standard deviations, and reliabilities of the instruction scales. Response format for the instruction scales also consisted of a five-point Likert scale ranging from (1) strongly disagree to (5) strongly agree. The analyses were performed with the mean scores of the items averaged within each scale, which therefore ranged from 1 to 5.

Table 2. Descriptive statistics of the instruction scales

\begin{tabular}{|c|c|c|c|c|c|}
\hline Instruction scales & Item examples & $n_{i}$ & $\alpha$ & M & SD \\
\hline $\begin{array}{l}\text { I. Interlinking and practical } \\
\text { application }\end{array}$ & $\begin{array}{l}\text { 'When I do math exercises, my teacher } \\
\text { shows me how I can apply the learning } \\
\text { material in everyday life.' }\end{array}$ & 4 & .68 & .3 .11 & 0.89 \\
\hline 2. Enthusiasm & $\begin{array}{l}\text { 'In math class, our teacher tries to } \\
\text { enthuse the students for the subject.' }\end{array}$ & 5 & .83 & 3.37 & 0.97 \\
\hline 3. Variety & $\begin{array}{l}\text { 'Our math teacher is good at arranging } \\
\text { math class in a diversified way.' }\end{array}$ & 3 & .71 & 3.30 & 1.03 \\
\hline 4. Student-adaptive instruction & $\begin{array}{l}\text { 'Our math teacher pays attention that all } \\
\text { students understand the course material.' }\end{array}$ & 4 & .84 & 3.40 & 1.01 \\
\hline 5. Granting of autonomy & $\begin{array}{c}\text { 'Our math teacher gives us a chance to try } \\
\text { our own solutions for solving problems.' }\end{array}$ & 3 & .68 & 3.35 & 0.84 \\
\hline 6. Positive reinforcement & $\begin{array}{l}\text { 'My teacher compliments me on good } \\
\text { results in math class.' }\end{array}$ & 3 & .85 & 3.29 & 1.14 \\
\hline 7. Punishment for failure & $\begin{array}{l}\text { 'My teacher scolds me on bad results in } \\
\text { math class.' }\end{array}$ & 3 & .63 & 2.02 & 0.89 \\
\hline 8. Support after failure & $\begin{array}{l}\text { 'My teacher shows how I can learn something } \\
\text { from mistakes I made in math exercises.' }\end{array}$ & 4 & .84 & 3.02 & 1.04 \\
\hline
\end{tabular}

Note. $N=1,380 . M$ and $S D$ refer to the mean score of the items averaged within each scale and can therefore range from $\mathrm{I}$ to 5 .

Based on the theoretical relevance of instructional quality with respect to experience of boredom, the scales were as follows: an (1) interlinking and practical application scale $\left(n_{i}=4\right)$ assessed the degree to which students learn about the everyday use of 
certain mathematics and how they are connected with other exercises and fields they dealt with earlier. The second scale measured to which extent students perceived (2) enthusiasm $\left(n_{i}=5\right)$ of their mathematics teacher during class. The (3) variety scale $\left(n_{i}=\right.$ 3) gauged how much students experience their teacher's instruction as monotonous. The degree to which math teachers gave comprehensive explanations and individual adjustment of the demands to their students was assessed by the (4) student-adaptive instruction scale $\left(n_{i}=4\right)$. A (5) granting of autonomy scale $\left(n_{i}=3\right)$ tested the amount to which students felt they received opportunities to try out their own problem solving strategies and solutions. A (6) positive reinforcement scale $\left(n_{i}=3\right)$ measured to which extent pupils received positive feedback for good achievement. Dealing with failure was assessed with scales for (7) punishment for failure $\left(n_{i}=3\right)$, and (8) support after failure $\left(n_{i}=4\right)$.

The instruction scales showed good internal consistency, with Cronbach's alpha higher than $.70(\mathrm{Mdn}=.79, \min =.63, \max =.85$, see Table 2$)$ for the majority of the scales and the remaining slightly below this level (i.e., interlinking and practical application $\alpha=.68$, granting of autonomy $\alpha=.68$, and punishment after failure $\alpha=$ .63). The slight differences in scale reliabilities influence manifest scores by generally underestimating the true values. This issue was resolved by using the latent factor scores of the instruction scales when testing the validity of the Precursors to Boredom Scales. These analyses were performed with Mplus (Muthén \& Muthén, 1998-2007). This software provides the opportunity to take the hierarchical structures of our data into account (students nested within classes). Standard errors resulting from routine standard procedures are typically downwardly biased (Hox, 2002) which is compensated for by Mplus.

Intra-class correlations were conducted with all scales. For the Precursors to Boredom Scales, intra-class correlations ranged from ICC $=.08$ for under-challengement to ICC $=$ .25 for teacher dislike, with a Median ICC $=.11$. For external validation, the intra-class correlations of the instruction scales ranged from ICC $=.16$ for punishment to ICC $=.29$ for enthusiasm, with a Median ICC $=.24$. Math grades showed an intra-class correlation of ICC $=.25$. These coefficients are in accordance with our assumption of experience of precursors to boredom to be rather individual compared to the report of instructional quality, which is part of a shared perception among all individuals in one classroom. We therefore interpreted the intra-class correlations as affirmation of our scales in order to perform the analyses intended.

\section{Results}

\section{Frequency of boredom}

The frequency of boredom in mathematics classes was analysed first. Overall, the frequency of boredom scale revealed that a large number of students were experiencing boredom in their math class $(M=2.76, S D=1.18)$. The analyses were performed with the mean scores of the items averaged within the frequency of boredom scale and therefore range from 1 to 5 where higher scores represent on average higher agreement on the statements. Of the students, $20.1 \%$ agreed or strongly agreed $(M \geq 4)$ with the statements 'I'm often bored in math class' and 'In math class, I frequently feel bored'. When taking those students into account who partly agreed $(M \geq 3)$ with the items, the number of bored pupils increases to $44.3 \%$ in our sample. 


\section{Structural validity}

To examine the structure of the Precursors to Boredom Scales, we compared a model with one general factor, as well as a hierarchical model consisting of a higher-order factor and eight second-order factors of precursors of boredom, to our assumed eight-factor model. If the eight-factor model was found to be superior to the competing models, this would be evidence for the hypothesized separation of the scales. We therefore performed a ML-CFA separately for each of the three models. Table 3 shows the models' fit to the data. Both the fit indices and information criteria demonstrate the superiority of the eight-factor model over both alternative models.

Table 3. Competing models' fit to the data

\begin{tabular}{lcccccccc}
\hline Model & $\chi^{2}$ & $\mathrm{~d} f$ & $p$ & $\mathrm{CFI}$ & $\mathrm{TLI}$ & $\mathrm{RMSEA}$ & $\mathrm{AIC}$ & $\mathrm{BIC}$ \\
\hline One-factor model & $3,651.38$ & 135 & $<.01$ & .56 & .50 & .14 & $73,739.87$ & $74,022.28$ \\
Hierarchical model & $1,140.30$ & 127 & $<.01$ & .87 & .85 & .08 & $70,602.31$ & $70,926.56$ \\
Eight-factor model & 365.46 & 107 & $<.01$ & .97 & .95 & .04 & $69,644.41$ & $70,073.25$ \\
\hline
\end{tabular}

Note. The one-factor model consists of one general factor causing boredom, the hierarchical model consists of a higher order factor and eight second-order factors of antecedents to boredom, the eight-factor model consists of our eight Precursors to Boredom Scales as factors.

\section{Scale reliabilities, measurement models, and intercorrelations}

Each of the Precursors to Boredom Scales had a Cronbach's alpha greater than or equal to $.70(\mathrm{Mdn}=.78, \min =.69, \max =.88$, see Table 4$)$, with the exception of the boredom due to an unchanging routine scale $(\alpha=.69)$. These rather high reliabilities may be due to the theoretical constructs represented by our scales being concise and therefore the items of each scale being quite close. The corrected itemtotal correlations of all items were $r_{i(t-i)} \geq .45(\mathrm{Mdn}=.60, \min =.45, \max =.79)$. Overall, the Precursors to Boredom Scales demonstrated strong internal consistency. Table 4 also shows measurement models for each of the Precursors to Boredom Scales and demonstrates good fit of our scales to the data.

Table 4. Reliabilities, corrected item-total correlations, and measurement models of the Precursors to Boredom Scales

\begin{tabular}{|c|c|c|c|c|c|c|c|c|c|}
\hline \multirow[b]{2}{*}{ Boredom scales } & \multirow[b]{2}{*}{$\alpha$} & \multicolumn{3}{|c|}{$r_{i(i-j)}$} & \multicolumn{5}{|c|}{ Measurement models } \\
\hline & & Mdn & Min & Max & $x^{2}$ & $d f$ & $\mathrm{CFI}$ & TLI & RMSEA \\
\hline I. Monotony & .69 & .51 & .48 & .56 & 33.74 & 2 & .95 & .93 & .11 \\
\hline 2. Lack of meaning & .81 & .62 & .59 & .68 & 40.23 & 5 & .98 & .98 & .07 \\
\hline 3. Opportunity costs & .80 & .67 & .67 & .67 & 8.07 & I & .99 & .99 & .07 \\
\hline 4. Being over-challenged & .79 & .60 & .53 & .66 & 44.05 & 5 & .95 & .94 & .08 \\
\hline 5. Being under-challenged & .72 & .57 & .57 & .57 & 13.28 & I & .95 & .95 & .09 \\
\hline 6. Lack of involvement & .76 & .61 & .61 & .61 & 46.88 & 1 & .92 & .92 & .18 \\
\hline 7. Teacher dislike & .88 & .79 & .79 & .79 & 1.12 & 1 & 1.00 & 1.00 & .01 \\
\hline 8. Generalized boredom & .70 & .51 & .49 & .56 & 38.94 & 2 & .94 & .90 & .12 \\
\hline
\end{tabular}




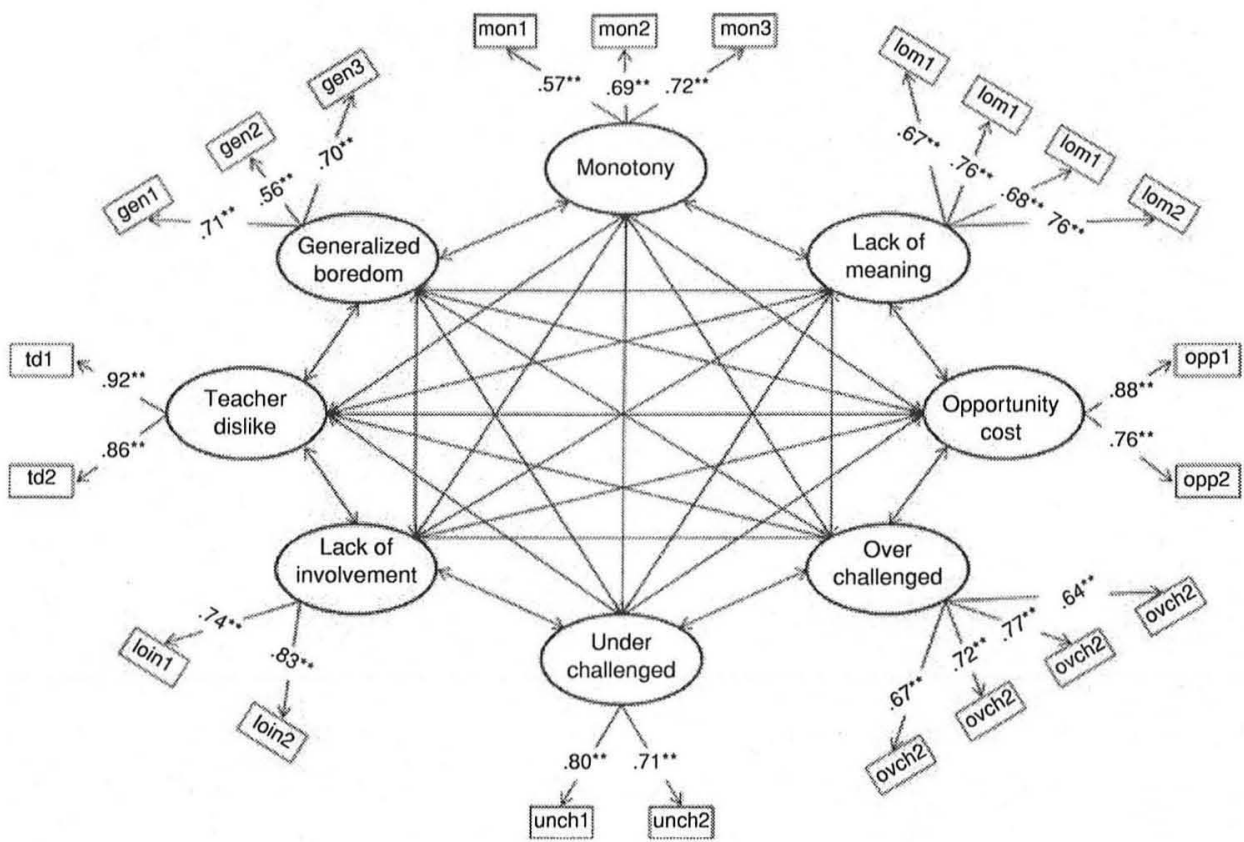

Figure I. Structure of the eight-factor model of Precursors to Boredom. Note. The figure shows the structure of the eight-factor model of Precursors of Boredom. A circle indicates a factor (latent variable), a rectangle indicates an item (observed variable).

Figure 1 shows the structure of our eight-factor model with items loading on their corresponding boredom factor. The latent intercorrelations of the Precursors to Boredom Scales are depicted in Table 5. The significant correlations between the latent factors of precursors to boredom ranged from $r=.10$ to $.75(\mathrm{Mdn}=.46)$. The largest positive correlations were between boredom due to a lack of involvement and boredom due to teacher dislike, as well as between boredom due to opportunity costs and boredom due to a lack of meaning. The largest negative correlation was observed between boredom due to being over- and under-challenged. The under-challenged scale showed the weakest relations with the other precursor scales, including several non-significant correlations with boredom due to teacher dislike and lack of involvement. Overall, the correlations

Table 5. Latent intercorrelations of the Precursors to Boredom Scales in the ML-CFA

\begin{tabular}{lcccccccc}
\hline & $\mathrm{I}$ & 2 & 3 & 4 & 5 & 6 & 7 & 8 \\
\hline I. Monotony & - & & & & & & \\
2. Lack of meaning & $.46^{* * * *}$ & - & & & & & \\
3. Opportunity costs & $.47^{* * * *}$ & $.72^{* * *}$ & - & & & & \\
4. Being over-challenged & $.36^{* * * *}$ & $.65^{* * * *}$ & $.49^{* * * *}$ & - & & & \\
5. Being under-challenged & $.32^{* * * *}$ & $-.28^{* * * *}$ & $-.24^{* * *}$ & $-.49^{* * * *}$ & - & & \\
6. Lack of involvement & $.53^{* * * *}$ & $.44^{* * * *}$ & $.38^{* * *}$ & $.56^{* * * *}$ & -.07 & - & \\
7. Teacher dislike & $.46^{* * *}$ & $.45^{* * *}$ & $.41^{* * *}$ & $.43^{* * *}$ & -.08 & $.75^{* * *}$ & - & \\
8. Generalized boredom & $.56^{* * * *}$ & $.60^{* * * *}$ & $.61^{* * *}$ & $.29 * * *$ & $.10^{*}$ & $.34^{* * * *}$ & $.36^{* * *}$ & - \\
\hline
\end{tabular}

$* p<.05 ; * * * p<<.001$. 
indicated that the scales are strongly related, yet measure different aspects of students' ascriptions of the causes of their boredom. Previous studies have reported correlations of latent factors up to $r=.90$ as still representing separable constructs (e.g., Bong, 2001). It is also important to note that these coefficients were corrected for unreliability and thus represent the highest possible coefficients derivable from this data.

\section{Gender differences in precursors of boredom}

To test for differences between males and females in their reported precursors to boredom, we integrated students' gender as a dummy variable into our model. Gender was coded with lower scores ( 0 ) for boys and higher scores (1) for girls. We analysed the correlations of gender with the latent factors of the Precursors to Boredom Scales, taking the nested structure of our data into account (ML-CFA). Thus, these correlations can be interpreted as measures of the effect size. We found positive effects (Cohen, 1988) for boredom due to being over-challenged $(r=.21, p<.001)$, experiencing a lack of meaning $(r=.19, p<.001)$, and opportunity costs $(r=.11, p<.01)$, and a negative effect of under-challenged $(r=-.15, p<.001)$. In other words, girls were more likely to be bored due to being over-challenged, perceiving a lack of meaning, and opportunity costs in their math class, whereas boys were more likely to be bored due to being under-challenged.

\section{Precursors of boredom and mathematics grades}

For further external validation of the Precursors to Boredom Scales, the correlations of mathematics grades with the boredom factors were calculated and can be found in Table 6 . The relationship between math grades and the precursors of boredom was quite differential. Most evident was the highly negative correlation with the scales of boredom due to being over-challenged, as well as the positive correlation with boredom due to being under-challenged. But also boredom due to a lack of meaning and due to opportunity costs provided a considerably negative correlation with math grades.

\section{Test of convergent validity}

A final ML-CFA was conducted with a 16-factor model that included the eight Precursors to Boredom Scales as well as the eight instruction scales. The model was analysed using a ML-CFA and showed a strong fit to the data: $\chi^{2}=1,625.22, d f=545, p<.001$, CFI $=$ $.95, \mathrm{TLI}=.93, \mathrm{RMSEA}=.04$. This analysis confirmed a close linkage between the newly developed boredom scales and the quality of instruction scales. The correlations of the latent factors from the ML-CFA are shown in Table 6.

As hypothesized, a number of strong relationships between the Precursors to Boredom Scales and instructional quality scales were found. There were boredom scales that showed consistently high or low correlations with all of the aspects of instruction quality. For instance, the scales of boredom due to teacher dislike and lack of meaning both showed high correlations with most of the instruction scales. Alternatively, there were low but significant correlations between the generalized boredom scale and all instructional quality scales. Also, being under-challenged as an antecedent of boredom had low linkages with most aspects of instructional quality.

There were also instruction scales that showed a differential pattern; specifically, high correlations with some precursor scales and low correlations with others. For 
Table 6. Correlations of the latent variables in the ML-CFA

\begin{tabular}{|c|c|c|c|c|c|c|c|c|}
\hline & Monotony & $\begin{array}{l}\text { Lack of } \\
\text { meaning }\end{array}$ & $\begin{array}{l}\text { Opportunity } \\
\text { costs }\end{array}$ & $\begin{array}{c}\text { Being } \\
\text { over-challenged }\end{array}$ & $\begin{array}{c}\text { Being } \\
\text { under-challenged }\end{array}$ & $\begin{array}{c}\text { Lack of } \\
\text { involvement }\end{array}$ & $\begin{array}{l}\text { Teacher } \\
\text { dislike }\end{array}$ & $\begin{array}{c}\text { Generalized } \\
\text { boredom }\end{array}$ \\
\hline Interlinking and practical application & $-.26 * * \%$ & $-.42 * * *$ & $-.36 * * *$ & $-.42^{* k+k}$ & $.23 * * *$ & $-.53 * * *$ & $-.53 * \% *$ & $-.24 * * * *$ \\
\hline Enthusiasm & $-.36 * 2 \%$ & $-.39 \% \%$ & $-.33^{* 0 \%}$ & $-.38 \% 0 \%$ & $.16 \%$ & $-.60 * * \%$ & $-.65^{* \% k}$ & $-.24 * * *$ \\
\hline Variety & $-.57^{* * * *}$ & $-.52 * * *$ & $-.47^{* * * * ;}$ & $-.47^{* * 1 \% *}$ & $.16 \%$ & $-.63^{* * * *}$ & $-.69 * 1 *$ & -.40 *** \\
\hline Student-adaptive instruction & $-.39 * * *$ & $-.49 * 2 * *$ & $-.38 * * \%$ & $-.59 * 0 \% *$ & $.26 * \% *$ & $-.69 * * \%$ & $-.63 \%$ & $-.30^{* \% k}$ \\
\hline Granting of autonomy & $-.30 \% * \%$ & $-.36 \% \% * k$ & -.30 \%okk & $-.35 \%$ & $.15^{* * *}$ & $-.52 * * *$ & $-.55^{* \% *}$ & $-.23^{* * * *}$ \\
\hline Positive reinforcement & $-.25 * * *$ & -.34 *⿻丷木 & $-.29 * * *$ & $-.28 * 1 \%$ & $.17^{* 1 * k}$ & $-.43 * k *$ & $-.48^{* 10 k}$ & $-.23^{* 11 k}$ \\
\hline Punishment for failure & $.38 * * * *$ & $.28 * * *$ & $.21 * 0 \%$ & $.37^{* * 1 k *}$ & -.01 & $.52 \% *$ & $.54 \% \%$ & $.19 * *$ \\
\hline Support after failure & $-.28 * k * *$ & $-.39 \% 1 \%$ & $-.32^{* \% 1 \%}$ & $-.37^{* k 1 \% k}$ & $.20 * * * *$ & $-.51 * k *$ & $-.52 * \%$ & $-.25^{* * *}$ \\
\hline Math grades & -.05 & $-.41 * * *$ & $-.28 * * *$ & $-.62^{* 1 \% *}$ & $.44^{* * * *}$ & $-.18 * 2 * k$ & $-.15^{*}$ & $-.13^{*}$ \\
\hline
\end{tabular}

$* p<.05 ; * * p<.01 ; * * * p<.001$. 
example, the variety instruction scale had high negative correlations with the precursor scales of boredom due to teacher dislike, lack of involvement, as well as unchanging routine; however, medium correlations were found with most of the other Precursors to Boredom Scales. Also, student-adaptive instruction had rather strong linkages with the precursor scales of boredom due to being over-challenged, teacher dislike, and lack of involvement; whereas relations with the other Precursors to Boredom Scales were only medium to low.

Another prominent result was that students who perceived more enthusiasm by their teacher were less likely to experience boredom due to teacher dislike. Similarly, students who received mathematics instruction with intensive interlinking and practical application felt less bored due to a lack of meaning. Overall, the pattern of results that emerged from this ML-CFA provided good support for the convergent validity of the Precursors to Boredom Scales.

\section{Discussion}

Boredom is a frequent emotion among students in class and may be provoked by different causes. The main goal of the present study was to examine if the assumed precursors are distinguishable empirically in order to prove that boredom is indeed due to different predictors. The following summarizes and discusses our results on the frequency of boredom, the measurement and validity of the precursors of boredom, and the relationship of the new boredom scales to gender, math grades, and aspects of classroom instruction.

\section{Frequency of boredom}

We found boredom to be a common emotion among students. Of our participants, 44.3\% were partly to strongly in agreement that they frequently experienced boredom in mathematics class. This result underlines the importance of research on boredom in school. The dissipation of human resources resulting from instructing young people in a way that leads to such a common occurrence of boredom is something that knowledgeand achievement-orientated societies must avoid. Therefore, it is necessary to understand the reasons for this emotion and explore the conditions under which boredom most commonly occurs.

\section{Structural validity of the Precursors to Boredom Scales}

In line with our hypotheses, we found support for separate antecedents of students' boredom. Our first analysis distinguished between several different precursors to boredom resulting in support for the structural validity of the scales. Furthermore, the scales' intercorrelations showed a diverse pattern of strong and weak connections between the assumed causes of boredom, which underlines our hypothesis of boredom being due to distinguishable precursors.

The noticeably strong relationship that was found between boredom due to teacher dislike and boredom due to a lack of involvement is logical. On the one hand, students who do not feel very integrated in the interactions during their mathematics course may dislike their teacher more, and thus feel bored in class. On the other hand, if students like their teacher they might participate more actively during class and be less bored. 
Clearly, both the teacher dislike and lack of involvement precursors of boredom seem to be provoked by the students' attitude towards the teacher. The precursor scales for lack of meaning and opportunity costs also had a high correlation that was highly plausible: if a teacher does not succeed in moderating the meaning of the course material to students, they may prefer doing other things than participate in math class. This result follows Mitchell's (1993) finding that meaningful learning material can prevent students boredom.

On the other end of the spectrum, there was found to be a clear divergence between being under- and over-challenged, which was marked by the moderately high negative correlation of those two boredom scales. Nevertheless, a correlation of $r=-.49$ makes multidimensionality rather evident: being over- or under-challenged does not represent opposite poles of a single, unidimensional construct (cf. Acee et al., 2010; Ahmed, 1990; Vodanovich \& Kass, 1990; Vodanovich, Wallace, \& Kass, 2005). There seem to be students who feel over-challenged by some course material and under-challenged by other exercises. This could be due to the diversity of mathematics subject material, since students are confronted with very heterogeneous contents and exercises (Heinze, Reiss, \& Rudolph, 2005). Also, it is possible that teachers sometimes recognize the problem of diversity in students' achievement levels and try to compensate by adjusting the level of their class demands in order to not over challenge the weak students or under challenge the stronger ones. In such cases, teachers may reduce boredom more by integrating individualized instruction methods in order to give each pupil the opportunity to work efficiently on their level of achievement.

The under-challenged boredom precursor showed rather low correlations with all the precursors except for boredom due to being over-challenged. Therefore, being under-challenged as a precursor of boredom seems to be a more independent construct. This might be because students who ascribe their boredom to being under-challenged should perform well in general, and should therefore not attribute their boredom to antecedents that are associated with low achievement or difficulties in understanding at the same time. In contrast, the over-challenged scale had medium to high correlations with all of the other Precursor to Boredom Scales, with the exception of generalized boredom. The affirmation of this interpretation can also be seen in the correlation of mathematics grades with the boredom scales. Specifically, being under-challenged is the only precursor to boredom correlating positively with math grades, whereas most of the other boredom scales show a negative relationship with math grades, and monotony is the only scale not correlating significantly with grades.

\section{Gender differences in the precursors of boredom}

We investigated whether boys and girls attributed their boredom in mathematics class to the same causes. We hypothesized that known gender differences in mathematical selfconcept and interest in mathematics (e.g., Goetz et al., 2008) would influence students' precursors of boredom. In line with our assumptions, the correlations revealed that girls scored lower on scales associated with self-concept and interest in mathematics than did boys.

Even though boys and girls have the same mean level of achievement in mathematics, there are disparities in self-concept and interest in mathematics (cf. Goetz et al., 2008). Our results showed that different genders perceived different factors as antecedents for their boredom. Girls attributed their boredom more to being over-challenged and less to being under-challenged, whereas boys displayed the inverse pattern. This goes in line 
with the findings on gender differences in self-concept wherein boys show generally more interest in mathematical matters than girls do (Frenzel et al., 2007a). Indeed, the current results showed that girls, when compared to boys, attributed their boredom more to a lack of seeing the usefulness of mathematics and preferring to do other things than be in math class. These patterns of attributing boredom to different precursors can lead to increasing the disparities in math self-concept and interest. Furthermore, among girls this may lead to decreased motivation as well as negative effects on enrolment in math courses, choice of college major, and long-term career decisions.

\section{Convergent validity of the Precursors to Boredom Scales with quality of instruction}

The results of our second analysis are very much in accordance with Pekrun's (2000, 2006) control-value theory of emotions. Specifically, students who took math classes with a high amount of instructor interlinking and practical application, as well as teacher enthusiasm and commitment, tended to more highly value the contents they learned in math class, and therefore felt less bored due to opportunity costs or a lack of meaning. These pupils seemed to profit from a deeper understanding of the material, and so perceived it as more useful and valuable.

Our results also suggest that Mikulas and Vodanovich's (1993) theory of boredom due to inadequately stimulating situations can be interpreted in several ways. Generally, the linkage with student-adaptive instruction was strongly related to over-challenging course material. Therefore, students in math classes that are too demanding and not understandable for them tend to see their boredom resulting from being over-challenged. At the other end of the spectrum, being under-challenged also appeared to reflect a lack of adaption by the teacher to the students' abilities such that the instructor demanded too little of those students.

The theories by Hill and Perkins (1985) and Robinson (1975) that monotony is one of the main causes of boredom were also supported by our results. This was apparent based on the high mean score of boredom due to monotony scale. Specifically, students had a mean score of $M=2.70(S D=1.32$, range $1-5)$ for the statement 'When I'm bored in math class it's because the course of events is always the same in math class'. Another indicator of the content validity of our monotony scale was its close connection with variety of instruction.

The fact that the scale of generalized boredom had a rather low negative correlation with most of the instruction scales shows that there might be students who feel bored regardless of the quality of their mathematics class. The reason for their boredom might be in their personality rather than in their perception of instruction. This goes in line with our theoretical assumption that some individuals have a stronger tendency to be bored than others (cf. also Fisher, 1993; Pekrun, 2000, 2006).

However, our results also show that boredom due to teacher dislike and a lack of involvement have rather high linkages with all of the instruction scales. It is therefore possible that students who like their teacher and who feel involved in instruction activities tend to describe their math class in a more favourable way. This may be because students do not always distinguish between qualities of their instruction and qualities of their teacher.

Support for Fenichel's $(1934,1951)$ proposed precursors of boredom, specifically 'when we must not do what we want to do, or must do what we do not want to do' (p. 359) was also reflected in our results. The items of the boredom due to opportunity costs scale showed the highest mean scores of our Precursors to Boredom Scales. For 
example, students' mean score was $M=3.75(S D=1.30)$ on the item 'When I'm bored in math class, it's because there would be much nicer things to do than sit in math class'. They might not value the course material as much as the material in other classes and therefore perceive mathematics as a dissipation of valuable time.

\section{Limitations}

The present study had several limitations that warrant further investigation of our research question in future studies. For example, we focused exclusively on boredom in mathematics classes due to the domain specific nature of academic emotions. A reasonable extension of our study would be to investigate precursors of boredom in other school subjects to determine if the structure of the scales would remain the same, and to draw comparisons of the mean values of each scale among different domains. Such a design for the comparison of the perception of boredom in different subjects could be accomplished rather easily by adapting the Precursors to Boredom Scales to other domains. Following theoretical and empirical evidence of precursors of boredom, it can be assumed that the structure of our boredom scales appears to be the same in other domains, whereas the mean values may vary considerably (Frenzel, Pekrun, \& Goetz, 2007b).

Also, our study was conducted with traditional trait questionnaires. As a consequence, the results reflect merely a disposition of perceiving boredom and habitual tendencies of attributing it to precursors. According to recent experience, sampling studies (Goetz et al., 2007; Hektner, Schmidt, \& Csikszentmihalyi, 2007), emotions depend considerably on the situation during which they are experienced. Therefore, boredom and its antecedents should also be assessed in state questionnaires; for example, by using experience sampling method or diary studies. Such a design would also allow for regression models predicting boredom through precursors of boredom investigated at previous measuring points.

Finally, the current scales were tested on German students. Not only may different school systems have an influence of students' perceptions of the precursors of boredom, but also culture in general could play an important role. It is conceivable that pupils with different cultural backgrounds perceive the causes of this emotion in different ways. It would be very valuable to investigate participants of different nationalities in order to draw comparisons among different school systems, how students' perception of instructional quality differs in different countries, and in which ways different students interpret the antecedents of their experience of boredom.

\section{Implications}

In view of the finding that $44.3 \%$ of the students experience boredom to some degree during the time spent in class, further knowledge of the precursors of boredom in school is important. This knowledge can aid our understanding of the in-class mechanisms that contribute to students' boredom, which has implications for teachers and researchers. For example, it would be useful for teachers who perceive a lot of boredom among their students to be aware of the reasons boredom occurs in order to go about reducing it. Therefore, they might explore the precursors of their students' boredom with the proposed scales. The mean scores of the students' answers on the scales can serve as hints for the teacher on which aspects to stress on for an improvement of his or her instructional quality. For instance, if boredom among students was occurring because 
of poorly adapted instruction, then the teacher could improve the situation by taking individual abilities of his students into account and by instructing in a more differentiated way. In order to establish the Precursors to Boredom Scales for the use in class evaluations, they would have to be standardized on a large and representative population of pupils first. Such norming procedures can serve as calibration for comparison with individual scores on each scale.

Furthermore, the knowledge of the mechanisms fostering boredom can help to develop prevention and intervention programmes with respect to reducing boredom at school. One could create such a programme with various solutions according to these different antecedents of boredom. These solutions might be especially successful to be implemented in whole classes, since we explored close connections to aspects of classroom instruction.

A question which should be further investigated is if boredom is underestimated in existing studies. We found boredom to occur as a consequence of various factors, with one factor being generalized or dispositional boredom. This scale appeared to be rather independent from other boredom scales. Until now, most empirical studies were conducted without taking different precursors of boredom into account, therefore measuring only generalized trait boredom. Therefore, one could conclude that by considering boredom as due to several distinguishable reasons this emotion may occur even more frequently than past research has discovered. Therefore, boredom may deserve greater attention in educational research.

\section{References}

Abramson, E. E., \& Stinson, S. G. (1977). Boredom and eating in obese and non-obese individuals. Addictive Behaviors, 2(4), 181-185. doi:10.1016/0306-4603(77)90015-6

Acee, T. W., Kim, H., Kim, H. J., Kim, J.-I., Chu, H.-N. R., Kim, M., ... Wicker, F. W. (2010). Academic boredom in under- and over-challenging situations. Contemporary Educational Psychology, 35(1), 17-27. doi:10.1016/j.cedpsych.2009.08.002

Ahmed, S. M. S. (1990). Psychometric properties of the Boredom Proneness Scale. Perceptual and Motor Skills, 71(1), 963-966. doi:10.2466/PMS.71.7.963-966

Bong, M. (2001). Between- and within-domain relations of academic motivation among middle and high school students: Self-efficacy, task-value and achievement goals. Journal of Educational Psychology, 93(1), 23-34. doi:10.1037/0022-0663.93.1.23

Broadbent, D. E., \& Gath, D. (1979). Chronic effects of repetitive and nonrepetitive work. In C. J. Mackay \& T. Cox (Eds.), Response to stress: Occupationat aspects. London: International Publishers Corp.

Byrne, B. M. (2001). Structural equation modeling with AMOS: Basic concepts, applications, and programming. Mahwah, NJ: Erlbaum.

Cohen, J. (1988). Statistical power analysis for the behavioral sciences (Vol. 2). Hillsdale, NJ: Erlbaum.

Daschmann, E. C., Stupnisky, R. H., Nett, U. E., Wimmer, B. M., \& Goetz, T. (2010). Students' and teachers' perspectives on the antecedents of boredom: An interview study. Paper presented at the Annual Meeting of the American Educational Research Association 2010.

Fenichel, O. (1934). Zur Psychologie der Langeweile [On the psychology of boredom]. Imago Zeitschrift für psychoanalytische Psychologie, ibre Grenzgebiete und Anwendungen, 20, 270-281.

Fenichel, O. (1951). On the psychology of boredom. In D. Rapaport (Ed.), Organization and pathology of thought: Selected sources (pp. 349-361). New York: Columbia University Press.

Fisher, C. D. (1993). Boredom at work: A neglected concept. Human Relations, 46(3), 395-417. doi:10.1177/001872679304600305 
Fiske, D. W., \& Maddi, S. R. (1961). Functions of varied experience. Oxford: Dorsey.

Frenzel, A. C., Pekrun, R., \& Goetz, T. (2007a). Girls and mathematics - a 'hopeless' issue? A control-value approach to gender differences in emotions towards mathematics. European Journal of Psychology of Education, 22(4), 497-514. doi:10.1007/BF03173468

Frenzel, A. C., Pekrun, R., \& Goetz, T. (2007b). Perceived learning environment and students' emotional experiences: A multilevel analysis of mathematics classrooms. Learning and Instruction, 17(5), 478-493.

Giambra, L. M., \& Traynor, T. D. (1978). Depression and daydreaming: An analysis based on self-ratings. Journal of Clinical Psychology, 34(1), 14-25.

Goetz, T., Frenzel, A. C., Hall, N. C., \& Pekrun, R. (2008). Antecedents of academic emotions: Testing the internal/external frame of reference model for academic enjoyment. Contemporary Educational Psychology, 33(1), 9-33. doi:10.1016/j.cedpsych.2006.12.002

Goetz, T., Frenzel, A. C., Pekrun, R., Hall, N. C., \& Luedtke, O. (2007). Between- and within-domain relations of students' academic emotions. Journal of Educational Psychology, 99(4), 715-733. doi: 10.1037/0022-0663.99.4.715

Götz, T. (2004). Emotionales Erleben und selbstreguliertes Lernen bei Schülern im Fach Matbematik [Emotional experience and self-regulated learning among students in mathematics]. München: Herbert Utz Verlag.

Götz, T., Frenzel, A. C., \& Pekrun, R. (2007). Regulation von Langeweile im Unterricht. Was Schülerinnen und Schüler bei der 'Windstille der Seele' (nicht) tun [Regulation of boredom in class. As students at the 'wind of the soul' (not doing)]. Unterrichtswissenschaft, 35(4), 312-333.

Harris, M. B. (2000). Correlates and characteristics of boredom proneness and boredom. Journal of Applied Social Psychology, 30(3), 576-598. doi:10.1111/j.1559-1816.2000.tb02497.x

Heinze, A., Reiss, K., \& Rudolph, F. (2005). Mathematics achievement and interest in mathematics from a differential perspective. Zentralblatt für Didaktik der Mathematik, 37(3), 212-220. doi:10.1007/s11858-005-0011-7

Hektner, J. M., Schmidt, J. A., \& Csikszentmihalyi, M. (2007). Experience sampling metbod: Measuring the quality of everyday life. Thousand Oaks, CA: Sage Publications.

Heron, W. (1957). The pathology of boredom. Scientific American, 196, 52-56. doi:10.1038/ scientificamerican0157-52

Hill, A. B., \& Perkins, R. E. (1985). Towards a model of boredom. British Journal of Psychology, $76(2), 235-240$.

Hox, J. J. (2002). Multilevel analysis: Techniques and applications. Mahwah, NJ: Erlbaum.

Hulin, C., Cudeck, R., Netemeyer, R., Dillon, W. R., McDonald, R., \& Bearden, W. (2001). Measurement. Journal of Consumer Psychology, 10(1/2), 55-69. doi:10.1207/S15327663JCP1001\&2_ 05

Johnston, L. D., \& O'Malley, P. M. (1986). Why do the nation's students use drugs and alcohol? Self-reported reasons from nine national surveys. Journal of Drug Issues, 16(1), 29-66.

Landon, P. B., \& Suedfeld, P. (1969). Information and meaningfulness needs in sensory deprivation. Psychonomic Science, 17(4), 248.

Larson, R. W., \& Richards, M. H. (1991). Boredom in the middle school years: Blaming schools versus blaming students. American Journal of Education, 99(4), 418-443. doi:10.1086/443992

Leon, G. R., \& Chamberlain, K. (1973). Emotional arousal, eating patterns, and body image as differential factors associated with varying success in maintaining a weight loss. Journal of Consulting and Clinical Psychology, 40(3), 474-480. doi:10.1037/h0034562

Lohrmann, K. (2008). Langeweile im Unterricht [Boredom in class]. Münster: Waxmann.

Mikulas, W. L., \& Vodanovich, S. J. (1993). The essence of boredom. Psychological Record, 43(1), 3-12.

Mitchell, M. T. (1993). Situational interest in the secondary mathematics classroom. Dissertation Abstracts International, Vol 53 (9-A), Mar, 1993. pp. 3133.

Morton-Williams, R., \& Finch, S. (1968). Young school leavers; report of a survey among young people, parents, and teachers. London: HMSO. 
Muthén, L. K., \& Muthén, B. O. (2007). Mplus user's guide (5th ed.). Los Angeles, CA: Muthén \& Muthén.

Orcutt, J. D. (1984). Contrasting effects of two kinds of boredom on alcohol use. Journal of Drug Issues, 14(1), 161-173.

Pekrun, R. (2000). A social-cognitive, control-value theory of achievement emotions. In J. Heckhausen (Ed.), Motivational psychology of buman development (pp. 143-163). Oxford: Elsevier.

Pekrun, R. (2006). The control-value theory of achievement emotions: Assumptions, corollaries, and implications for educational research and practice. Educational Psychology Review, 18(4), 315-341. doi:10.1007/s10648-006-9029-9

Pekrun, R., Frenzel, A. C., Goetz, T., \& Perry, R. P. (2007). The control-value theory of achievement emotions: An integrative approach to emotions in education. In P. A. Schutz \& R. Pekrun (Eds.), Emotion in education (pp. 13-36). San Diego, CA: Elsevier Academic Press.

Pekrun, R., Goetz, T., Daniels, L. M., Stupnisky, R. H., \& Perry, R. P. (2010). Boredom in achievement settings: Exploring control-value antecedents and performance outcomes of a neglected emotion. Journal of Educational Psychology, 102(3), 531-549. doi:10.1037/a0019243

Pekrun, R., Goetz, T., Titz, W., \& Perry, R. P. (2002). Positive emotions in education. In E. Frydenberg (Ed.), Beyond coping: Meeting goals, visions, and challenges (pp. 149-173). Oxford: Oxford University Press.

Pekrun, R., Götz, T., Jullien, S., Zirngibl, A., vom Hofe, R., \& Blum, W. (2002). Skalenbandbuch PALMA: 1. Messzeitpunkt (5. Klassenstufe) [PALMA scales handbook: 1 measurement (5th grade)]. München: Institut Pädagogische Psychologie, Universität München.

Pekrun, R., vom Hofe, R., Blum, W., Frenzel, A. C., Goetz, T., \& Wartha, S. (2007). Development of mathematical competencies in adolescence: The PALMA longitudinal study. In M. Prenzel (Ed.), Studies on the educational quality of schools. The final report of the DFG Priority Programme (pp. 17-37). Münster: Waxmann.

Robinson, W. P. (1975). Boredom at school. British Journal of Educational Psychology, 45(2), 141-152.

Samuels, D. J., \& Samuels, M. (1974). Low self-concept as a cause of drug abuse. Journal of Drug Education, 4(4), 421-438.

Solomon, P. (1972). Sensory deprivation human behavior. Biological, psychological, and sociological. Oxford, UK: Atheneum.

Titz, W. (2001). Emotionen von Studierenden in Lernsituationen-Explorative Analysen und Entwicklung von Selbstberichtskalen [Emotions of students in learning situations, Exploratory analysis and development of Selbstberichtskalen]. Münster: Waxmann.

Vodanovich, S. J., \& Kass, S. J. (1990). A factor analytic study of the Boredom Proneness Scale. Journal of Personality Assessment, 55(1/2), 115-123. doi:10.1207/s15327752jpa5501\&2_11

Vodanovich, S. J., Wallace, J. C., \& Kass, S. J. (2005). A confirmatory approach to the factor structure of the Boredom Proneness Scale: Evidence for a two-factor short form. Journal of Personality Assessment, 85(3), 295-303. doi:10.1207/s15327752jpa8503_05

Wasson, A. S. (1981). Susceptibility to boredom and deviant behavior at school. Psychological Reports, 48(3), 901-902. 